\title{
ELECTRON MICROSCOPY OF THE L-CYCLE IN BACILLUS LICHENIFORMIS VAR. ENDOPARASITICUS (BENEDEK)
}

\author{
K. A. Bisset, Janice Tallack and Roberta Bartlett \\ Department of Bacteriology, University of Birmingham, Birmingham B15 2TJ
}

Plates XXXVI-XL

RECENT STUDIES in this laboratory (Bisset and Bartlett, 1978; Bartlett and Bisset, 1979) appear to confirm the view of Roberts (1964) and Pease (1974) that the spheroplasts and 'diphtheroid' bacteria, described by many workers, as occurring notably in patients with arthritis and cancer, are phases in the L-cycle of a Bacillus species, diagnosed in this laboratory as $B$. licheniformis var. endoparasiticus, (Benedek), abbreviated as BLE (Bisset, 1977). These forms can be isolated from the blood of many normal persons, and their true nature is indicated by occasional reversions to the sporogenous phase, in primary cultures incubated for prolonged periods (Bisset and Bartlett, 1978). Various substances, notably hog gastric mucin and diaminopimelic acid, induce an increased rate of reversion (Bartlett and Bisset, 1979).

Accurate descriptions of the life-cycle of this organism have been published on several occasions in the past half-century. Those, for example of Glover (1930) and Brehmer (1934), correspond closely with our own observations, and references to numerous, less satisfactory but perfectly recognisable, descriptions are listed by the contributors to a Symposium (1970) and by Mattman (1974). These have failed to carry conviction for two reasons; they are advanced as discoveries of the microbial pathogen of cancer or, less frequently, arthritis and other conditions, which they may or may not be, but for which no real proof is available; secondly, the essentially simple and normal behaviour of the bacillus, passing through its L-cycle, has not been understood by the investigators, who have been misled into descriptions of new, hitherto unknown types of micro-organism, with newly coined names. These were not acceptable to bacteriologists generally.

The purpose of this paper is to demonstrate by electron microscopy of sections the structure of the L-form and intermediate stages, to illustrate their relationship to one another, to the normal Bacillus stage, and to other bacteria.

\section{MATERIALS AND METHODS}

Bacteria. The organism mainly employed was a strain of BLE isolated from normal human erythrocytes (Bisset and Bartlett, 1978); it simultaneously produced spheroplasts and bacilli in

Received 27 Feb. 1979; accepted 8 Mar. 1979 
the intermediate 'diphtheroid' phase. Sporulating organisms, for comparison, were taken from cultures of a reverted strain in the Bacillus phase (Bisset and Bartlett, 1978).

Cultures were made by the methods previously described (Bisset and Bartlett, 1978), and examined after incubation for $c .3$ days and in subcultures. Spheroplasts were also studied in primary cultures (Bisset and Bartlett, 1978) several weeks old, and in their subcultures.

For electronmicroscopy, fixation was by glutaraldehyde followed by osmium tetroxide, as described by Glauert (1974). Sections, cut on either a Cambridge Huxley or an LKB microtome, were stained with uranyl acetate and lead citrate (Reynolds, 1963) and examined with an AE1 801A electron microscope. Preliminary microscopic examination was by phase contrast and by a variety of standard staining methods, especially the phosphomolybdic-acid and methyl-green procedure for cell walls (Bisset, 1970) and the technique of Schaeffer and Fulton (1933) for endospores.

\section{RESULTS}

The morphological range of the L-culture could be seen in methyl-greenstained preparations under the optical microscope (fig. 1); these showed a background of partially disrupted spheroplasts, lacking stainable cell-wall material (a); 'diphtheroid' bacilli with varying degrees of reaction to the dye (b, c); a few swollen filaments, characteristic of these organisms (d); and occasional forms which appeared to be sporulating (e), although mature endospores could not be identified in these intermediate L-forms, but only in the fully reverted Bacillus-type cultures (Bisset and Bartlett, 1978).

Sections under the electron microscope showed these differences more clearly. The spheroplasts appeared in roughly circular groups, subdivided by partial gaps; the cell wall was apparently of a single diffuse layer, and lacking in rigidity (figs. 2,3 ). Subcultures from the spheroplasts, commencing to revert to a bacillary form, were small and simple in outline with very thin walls, showing a tendency to adhere in small clumps that may have represented the continuance of the same arrangement as seen in the spheroplasts from which they had grown (figs. $4,5,6$ ). These were represented in the stained preparations by the small rods, reacting only faintly with the cell-wall stain (fig. 1b). The larger, more strongly developed or reverted, 'diphtheroid' rods, represented by the more robust and strongly stained rods (fig. 1c), were in most cases subdivided by a complete cross wall; the cell wall was of the normal gram-positive type (figs. 7, 8). Production of spore-like bodies was occasionally observed in the 'diphtheroid' cultures; these lacked the multiple-layered cell envelopes of a true spore, but appeared to be formed in a very similar manner (figs. 9-13). They did not stain as spores, and failed to survive at $60^{\circ} \mathrm{C}$ for more than a few minutes.

Cultures fully reverted to the sporogenous Bacillus-phase contained a large proportion of true endospores, provided with normal, complete, multiple-layered walls (figs. 14, 15). Such spores were resistant to $80^{\circ} \mathrm{C}$ for $4-5 \mathrm{~h}$, and to $100^{\circ} \mathrm{C}$ for $2-3 \mathrm{~min}$., and reacted positively with the spore stain. A proportion of bacilli contained thin-walled forespores, in the course of development. The latter bore some resemblance to the incomplete spore-like bodies produced by the 'diphtheroid' phase.

Sections of the large, swollen forms that many authors have described in 
this organism (see Mattman, 1974, for references) were without obvious internal structure, except for suggestions of transverse partitions that were apparently not of cell-wall material (figs. 16, 17). At high magnification the cell contents could be seen to consist of very small irregular particles (fig. 18).

\section{DisCUSSION}

The results recorded in this paper are consistent with the view that the spheroplast stage of the BLE organism is the L-form of a sporing bacillus, and that the smaller and larger, non-sporing bacilli, including 'diphtheroid' bacteria, that have so often been described from such sources as rheumatoid arthritis, are intermediate L-forms and part of the same cycle. So also are the small, thin-walled rods derived on subculture from spheroplasts; these are frequently acid-fast (Bisset and Bartlett, 1978) and have been described as mycobacteria by previous workers (Symposium, 1970); this observation bears upon repeated claims by investigators of the tubercle bacillus that this pathogen has a stage in which it simulates a sporing Bacillus (see Bisset, 1970 for references); the reverse may well be true.

The large swollen bodies that have been described very frequently, especially in strains derived from patients with cancer (Symposium, 1970), appear to be the mother cells of the L-form. Their very close resemblance to the mother cells of Rhizobium, which is also believed by some to be a specialised sporing bacillus (Bisset, 1952; Gillberg, 1969) and is associated with the production of tumours, albeit in plants, has previously been noted in this laboratory and was referred to by Pease (1970).

The occurrence, in the 'diphtheroid' bacilli, of structures that can reasonably be described as cell-wall-deficient spores, hardly detectable except in sections, by electron microscopy, is of some importance in supporting the postulated relationship between the 'diphtheroid' phase and the sporing bacillus itself. Such decadent sporulation mutants were recently reported in $B$. subtilis, which is closely related to $B$. licheniformis, by Balassa $e$ t al. (1979).

\section{SUMMARY}

Electronmicrographs of sections show that the L-phases of Bacillus licheniformis var. endoparasiticus (Benedek) simulate the various types of microorganism described by previous workers as associated with ostensibly noninfective conditions, notably cancer and arthritis; e.g., mycoplasmas, mycobacteria, corynebacteria and actinomycetes. The stages of the-L-cycle, from spheroplasts through smaller and larger 'diphtheroid' bacteria to the fully reverted sporogenous bacillus, differ from one another mainly in their degree of reconstitution of the cell envelopes. Occurrence in 'diphtheroids' of nonresistant, cell-wall-deficient spore-like bodies, confirms their relationship with the true sporing bacillus stage. Large, swollen forms appear to be mother cells of minute stages. 


\section{REFERENCES}

Balassa, G., Milhaud, P., Sousa, J. C. F. and Silva, M. T. 1979. Decadent sporulation mutants of Bacillus subtilis. J. gen. Microbiol., 110, 381.

BarTlett, R. AND BisSET, K. A. 1979. Induction of reversion from the L-form to the sporogenous phase of Bacillus licheniformis var. endoparasiticus (Benedek). J. med. Microbiol., $12,239$.

BisSET, K. A. 1952. Complete and reduced life cycles in Rhizobium. J. gen Microbiol., 7, 233.

Bisset, K. A. 1970. The cytology and life-history of bacteria, 3rd ed., Edinburgh, pp. 13-15 and 89-91.

BiSSET, K. A. 1977. Isolations of micro-organisms from arthritic patients and healthy normals. Ann. rheum. Dis., 36, 96.

Bisset, K. A. AND BARTLETT, R. 1978. The isolation and characters of L-forms and reversions of Bacillus licheniformis var. endoparasiticus (Benedek) associated with the erythrocytes of clinically normal persons. J. med. Microbiol., 11, 335 .

BREHMER, vON W. 1934. "Siphonospora polymorpha" n.sp. ein neuer Mikroorganismus des Blutes und seine Beziehung zür Turmorgenese. Medsche Welt, Berl. 8, 1179.

GILlBERG, B. O. 1969. Heat resistance and pigmented variants of Rhizobium. Nature, Lond. 222, 574.

Glauert, A. M. 1974. Practical methods in electron microscopy, Amsterdam, vol. 3, p. W3.

Glover, T. J. 1930. The bacteriology of cancer. Can. Lancet Pract., 74, 92.

Mattman, L. H. 1974. Cell wall deficient forms. Cleveland, Ohio, pp. 381-383.

PeAse, P. 1970. Microorganisms associated with malignancy. Ann. N.Y. Acad. Sci., part IV, discussion, 174, 782 .

PEASE, P. 1974. Identification of bacteria from blood and joint fluids of human subjects as Bacillus licheniformis. Ann. rheum. Dis., 33, 67.

REYNOLDS, E. S. 1963. The use of lead citrate at high $p \mathrm{H}$ as an electron opaque stain in electron microscopy. J. cell Biol., 17, 208.

ROBERTS, D. H. 1964. L-phase bacterial forms associated with infectious synovitis in chickens and turkeys. Res. vet. Sci., 5, 441.

SCHAEFFER, A. B. AND FULTON, M. 1933. A simplified method of staining endospores. Science, N.Y. 77, 194.

SYMPOSIUM. 1970. Microorganisms associated with malignancy, part IV. Ann. N.Y. Acad. Sci. $174,636$. 


\section{L-CYCLE IN BACILLUS LICHENIFORMIS}
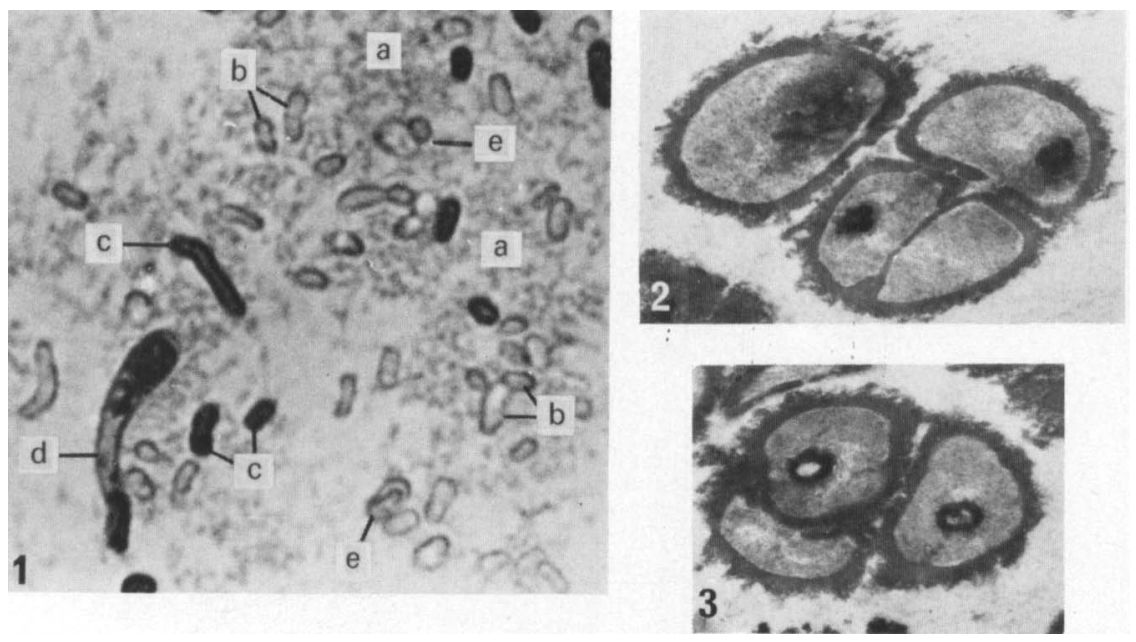

Fig. 1. Variety of morphology, as shown by cell-wall stain: (a) disrupted spheroplasts; (b) small, weaklystaining rods; (c) larger 'diphtheroid' rods, with stronger staining representing cell wall; (d) swollen filament; L-form mother cell; (e) spore-like bodies. $\times 1700$.

FIGs. 2 and 3.- Sections of spheroplasts in groups, showing weak, diffuse cell wall subdivided by gaps. EM. $\times 27000$.
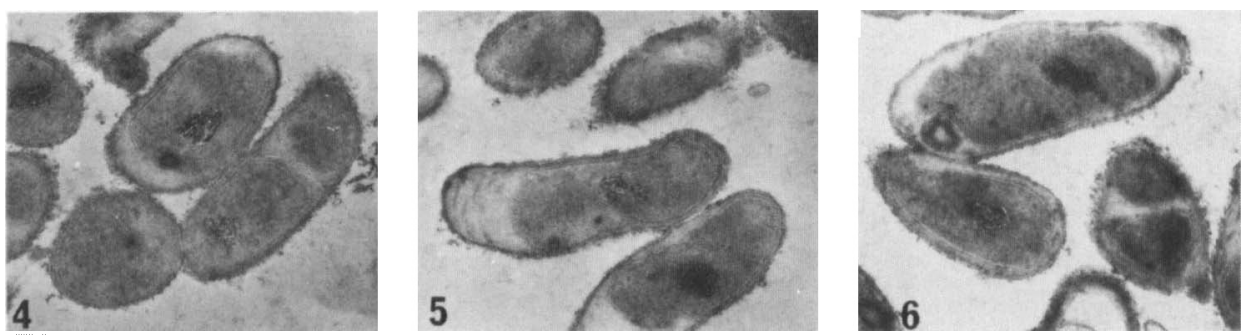

FIGS. 4. To 6.- Sections of small, thin-walled rods (as b in Fig. 1), adhering in groups. EM. $\times 27000$. 


\section{L-CYCLE IN BACILLUS LICHENIFORMIS}
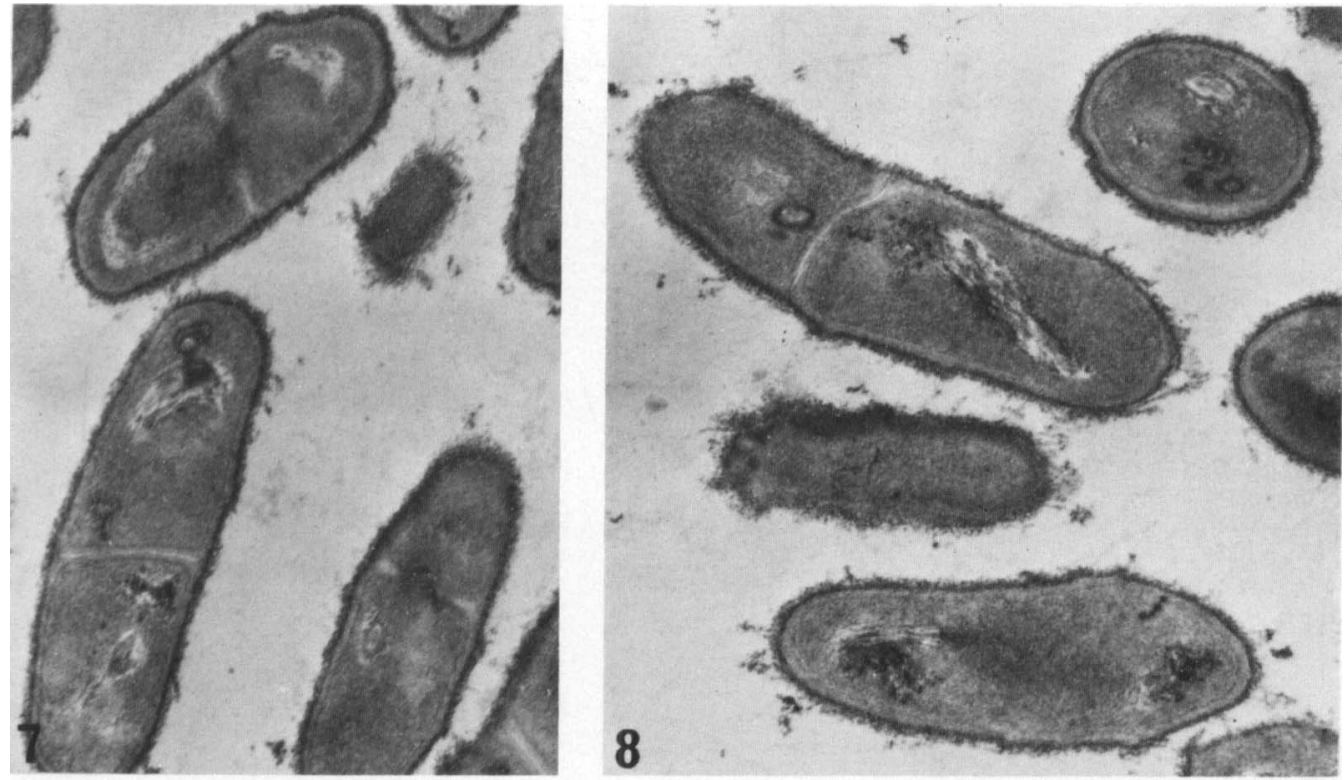

FIGS. 7 AND 8.- Sections of 'diphtheroid' rods, as (c) in fig. 1, with more complex wall and cross-walls. EM. $\times 40000$. 

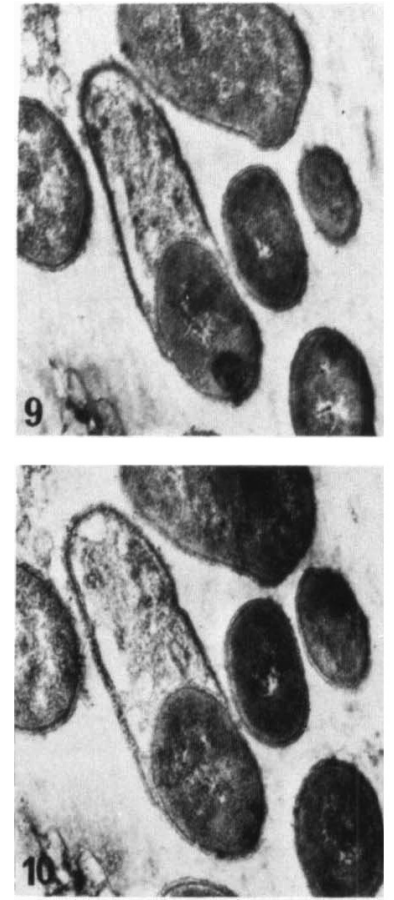
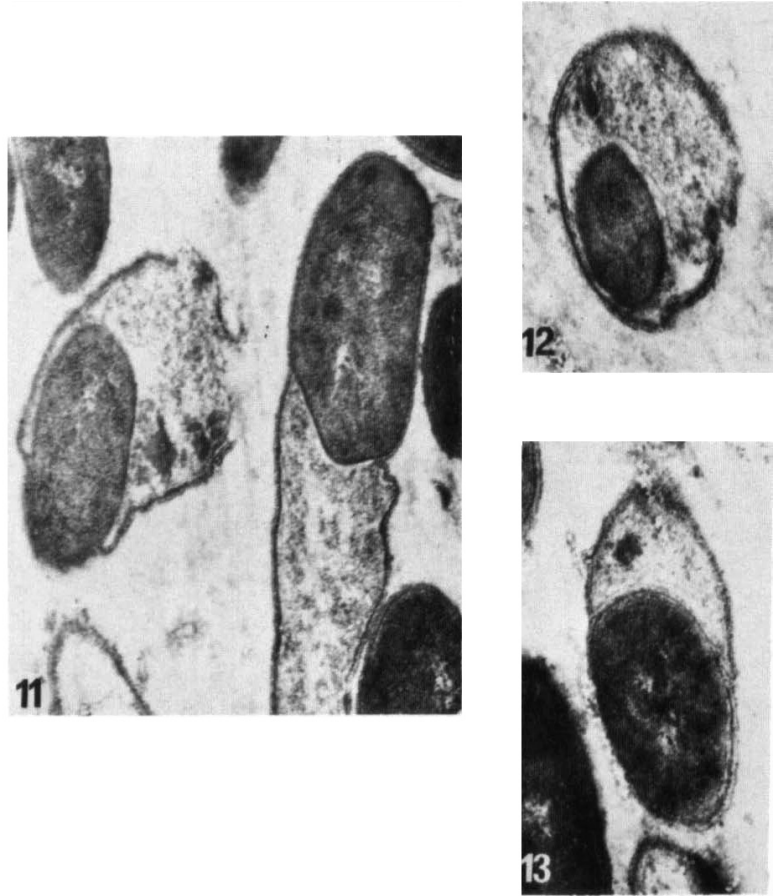

FIGS. 9 and 10.-Adjacent sections through 'diphtheroid' bearing spore-like body with granule (mesosome?), absence of which in second cut confirms granular nature. EM. $\times 30000$.

FIGS. 11 to 13.-Sections of spore-like bodies in 'diphtheroid' cells (as e in Fig. 1), showing lack of multiple spore wall, even in those apparently mature. EM. $\times 40000$. 


\section{L-CYCLE IN BACILLUS LICHENIFORMIS}
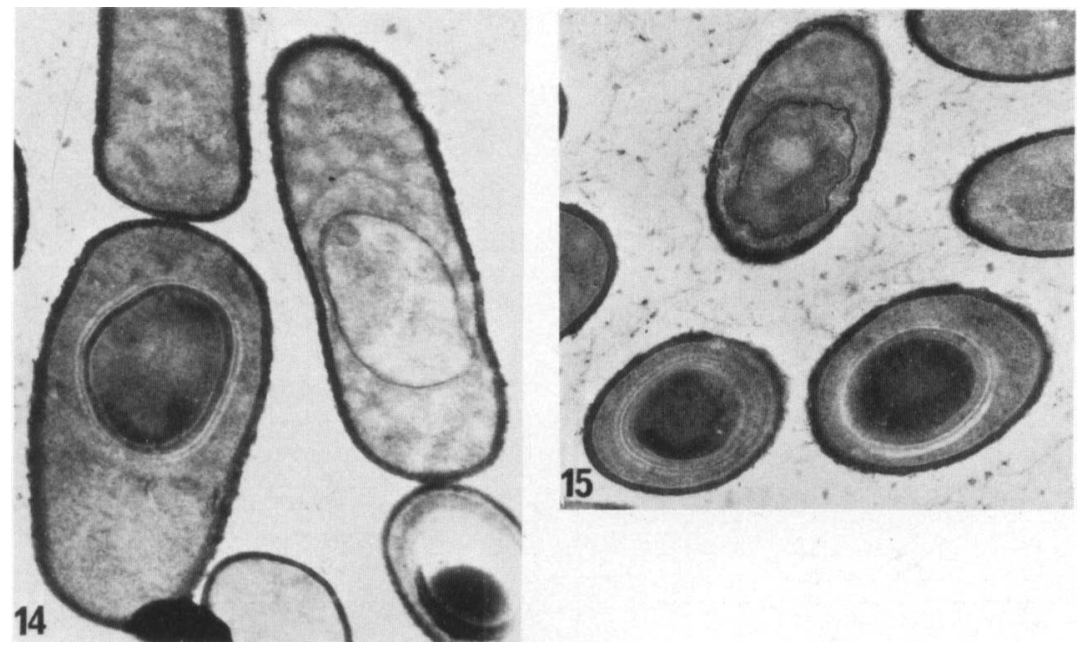

Figs. 14 and 15.- Sections of typical spores and prospores in completely reverted, Bacillus-like rods. EM. $\times 27000$. 

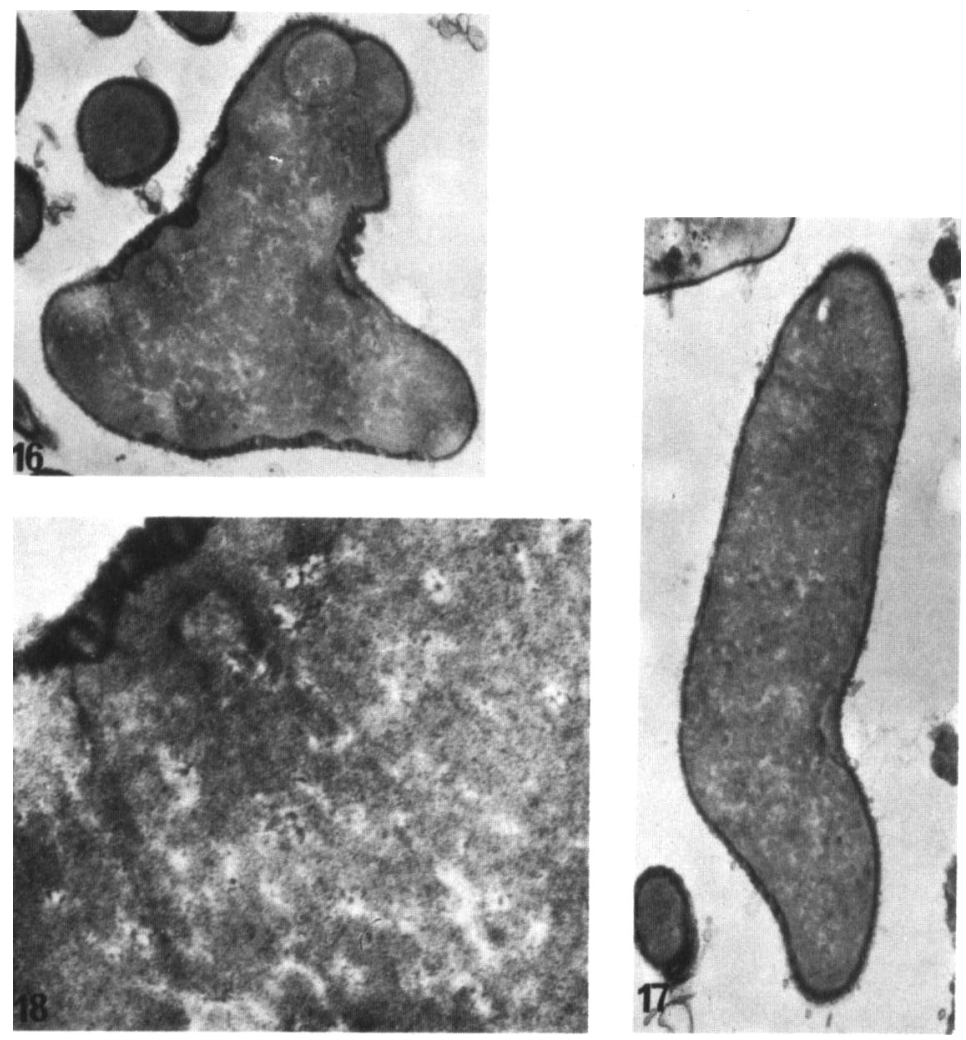

FIGS. 16 and 17.- Sections of swollen filaments, as (d) in fig. 1, characteristic of BLE and resembling the mother cells of Rhizobium. Contains largely undifferentiated granules with suggestions of cross-partitions, not of cell-wall material. EM. $\times 13500$.

FIG. 18.-Portion of fig. 16 enlarged, showing small, irregular granules with dark centres. EM. $\times 54000$. 